\title{
GH and insulin affect fatty acid synthase activity in isolated porcine adipocytes in culture without any modifications of sterol regulatory element binding protein-1 expression
}

\author{
I Louveau and F Gondret \\ Institut National de la Recherche Agronomique, Unité Mixte de Recherches sur le Veau et le Porc, 35590 Saint Gilles, France \\ (Requests for offprints should be addressed to I Louveau; Email: louveau@st-gilles.rennes.inra.fr)
}

\begin{abstract}
The ability of GH to decrease fatness and insulin-regulated events such as lipogenic enzyme activities is well known in pigs. Nevertheless, the precise mechanism underlying these actions has not been elucidated yet. Expression of the transcription factor sterol regulatory element binding protein (SREBP)-1 has been reported as a key mediator of insulin action in rat hepatocytes and adipose cell lines. The present study aimed to determine whether the regulation of lipogenesis by GH and/or insulin in porcine adipocytes also involved SREBP-1. Isolated adipocytes, obtained from perirenal or s.c. adipose tissue samples of female pigs $(51 \pm 0.4 \mathrm{~kg} ; n=17)$, were cultured in serum-free medium in the absence or presence of these hormones for
\end{abstract}

up to 4 days. Glucose incorporation and fatty acid synthase activity were increased by insulin in a dose-dependent manner in adipocytes of both sites. The increase was maximal at 1.7 and $17 \mathrm{nM}$ in s.c. and perirenal adipocytes respectively, suggesting inter-depot differences in the regulation of lipogenesis by insulin. These insulinstimulated events were decreased by GH $(1 \mathrm{nM})$. No change in SREBP-1 mRNA levels was observed in response to $\mathrm{GH}$ and/or insulin. Taken together, these data indicate that the regulation of lipogenesis by insulin and $\mathrm{GH}$ appears to not involve changes in SREBP-1 mRNA levels in porcine adipocytes.

Journal of Endocrinology (2004) 181, 271-280

\section{Introduction}

Growth hormone $(\mathrm{GH})$ is known to regulate adipose tissue growth and development in several species. A large number of studies have shown that chronic administration of GH to growing pigs causes a dramatic decline in adipose tissue lipid accretion (Etherton \& Bauman 1998, Etherton 2000). This effect is due primarily to a decrease in lipogenesis rather than to an increase in lipolysis, and involves a decrease in adipocyte insulin sensitivity. This leads to a marked decrease in insulin-regulated events such as glucose transport and lipogenic enzyme activities as assessed in vivo (Dunshea et al. 1992) and in vitro (e.g. Magri et al. 1990, Harris et al. 1993, Wang et al. 1999). The effect of $\mathrm{GH}$ on the regulation of fatty acid synthase (FAS), the key lipogenic enzyme that catalyzes all the reactions implicated in the conversion of acetyl-CoA and malonyl-CoA to palmitic acid, is especially well documented in pigs. Both activity and mRNA levels of FAS (Magri et al. 1990, Mildner \& Clarke 1991, Harris et al. 1993, Donkin et al. 1996) are decreased in adipose tissue of $\mathrm{GH}$-treated animals. It has also been shown that GH attenuates the stimulatory effect of insulin on FAS gene transcription in 3T3-F442A adipocytes (Yin et al. 1998, 2001). Nevertheless, the mechanism by which GH inter- feres with insulin action on FAS gene transcription has not been elucidated yet. The GH-dependent impairment of insulin action does not result from changes in insulin binding or insulin receptor kinase activity in porcine adipocytes (Magri et al. 1990). It is mediated by neither protein kinase A, protein kinase $\mathrm{C}$ nor Janus kinase-2 in 3T3-F442A adipocytes (Yin et al. 2001). Further studies are therefore required to identify the molecule(s) involved in this process. One possible candidate is the sterol response element binding protein (SREBP)-1c, a member of the helix-loop-helix-leucine zipper family of transcription factors, which has been reported to play a pivotal role in mediating the effects of insulin on gene expression in liver (Foufelle \& Ferré 2002). SREBP-1c is synthesized as a precursor form anchored into membranes of the endoplasmic reticulum and nuclear envelope. After proteolytic cleavage, the mature form constituted by the aminoterminal half of the precursor, enters the nucleus where it can bind both sterol regulatory elements and E-boxes on the target genes (Brown \& Goldstein 1997). Adenoviral-mediated overexpression of constitutively active SREBP-1c up-regulates FAS promoter activity and increases FAS mRNA levels in primary cultured rat hepatocytes (Foretz et al. 1999a) or 3T3-L1 adipocytes (Kim et al. 1998, Le Lay et al. 2002, Palmer et al. 2002). 
Conversely, adenoviral vectors expressing a dominant negative version of SREBP-1c block the effect of insulin on FAS mRNA in primary cultures of rat hepatocytes (Foretz et al. 1999b) and 3T3-L1 adipocytes (Le Lay et al. 2002). Transcription of SREBP-1c is controlled positively by insulin in isolated rat hepatocytes (Foretz et al. 1999b, Azzout-Marniche et al. 2000) and in 3T3-L1 adipocytes (Kim et al. 1998, Le Lay et al. 2002), thus leading to increased amounts of the precursor form and thus, of the nuclear mature form of SREBP-1c in insulin-treated cells (Azzout-Marniche et al. 2000). However, a recent study has shown that SREBP-1c gene expression is not modified by insulin in freshly isolated rat adipocytes (Palmer et al. 2002). The present study was undertaken to examine the regulation of lipogenesis by insulin and GH in isolated porcine adipocytes maintained in primary culture and to determine whether this regulation involves modification of SREBP-1 expression. Cells obtained from both s.c. and perirenal adipose tissue were studied, as depot-specific gene regulation in adipocytes has been suggested in rats and human (Lefebvre et al. 1998, Villafuerte et al. 2000).

\section{Material and Methods}

\section{Materials}

Porcine GH (AFP 11716C) was provided by Dr A F Parlow, National Hormone and Peptide Program (NHPP), National Institute of Diabetes, Digestive and Kidney Diseases (NIDDK), Bethesda, MD, USA. Insulin (Actrapid) was obtained from Novo Nordisk (Bagsvaerd, Denmark). Collagenase A $(0 \cdot 22 \mathrm{U} / \mathrm{mg})$ and protease inhibitors (COMPLETE) were purchased from Roche Applied Science (Meylan, France). Dulbecco's modified Eagle's medium (DMEM), Hepes, antibiotics and RTS labeling reagents (for random priming in the presence of $\left[\alpha-{ }^{32} \mathrm{P}\right]$ deoxycytidine triphosphate) were obtained from Invitrogen (Cergy-Pontoise, France). D- $\left[\mathrm{U}_{-}{ }^{14} \mathrm{C}\right]$ glucose (306 $\mathrm{mCi} / \mathrm{mmol}),\left[\alpha_{-}{ }^{32} \mathrm{P}\right]$ deoxycytidine triphosphate, ECL Western blot detection kits, Hybond C nitrocellulose and Hybond $\mathrm{N}^{+}$membranes were obtained from Amersham Biosciences (Orsay, France). RNAse-free DNAse was obtained from Ambion (Austin, TX, USA). Highly purified salt-free primers were generated from Proligo (Paris, France). The bicinchoninic acid protein assay kit was obtained from Pierce (Rockford, IL, USA). All other reagents were of analytical grade and were supplied by Sigma (St-Quentin-Fallavier, France) or Eurobio (Les Ulis, France).

\section{Adipose tissue collection, isolation and primary culture of porcine adipocytes}

The experiment was conducted in accordance with the national regulation for the human care and use of animals in research (certificate of authorization to experiment on living animals no.7676 delivered by the French Department of Agriculture to I Louveau).

Adipocytes were obtained by collagenase treatment of perirenal (leaf fat) or s.c. adipose tissue samples from Piétrain $\times$ (Large-White $\times$ Landrace) female pigs $(50 \cdot 9 \pm$ $0.4 \mathrm{~kg}$ in body weight; $100 \pm 2$ days of age; means \pm S.E.M.; $n=17$ ), as previously described (Etherton \& Chung 1981). Briefly, minced adipose tissue in Krebs-Ringerbicarbonate buffer $(3 \mathrm{ml} / \mathrm{g}$ of tissue) containing $3 \% \mathrm{BSA}$, $10 \mathrm{mM}$ glucose, $1.3 \mathrm{mg} / \mathrm{ml}$ collagenase and antibiotics, was shaken $(40$ r.p.m.) in a sterile polypropylene flask for $60 \mathrm{~min}$ at $37^{\circ} \mathrm{C}$. Digestion products were filtered through nylon mesh $(200 \mu \mathrm{m})$ and mature adipocytes were allowed to float. Cells were then washed by removing the infranatant using a plastic catheter attached to a syringe and adding $37^{\circ} \mathrm{C}$ DMEM, $5.5 \mathrm{mM}$ glucose. After three such washes, adipocytes were placed in DMEM containing $10 \mathrm{mM}$ Hepes, 1\% L-glutamine, $140 \mathrm{nM}$ hydrocortisone, and $62.5 \mathrm{U} / \mathrm{ml}$ penicillin and $62.5 \mu \mathrm{g} / \mathrm{ml}$ streptomycin. Cells were cultured to a final concentration of approximately $1-2 \times 10^{5} / \mathrm{ml}$ in a humidified $5 \% \mathrm{CO}_{2}$ atmosphere at $37^{\circ} \mathrm{C}$ for up to 4 days, in the absence or presence of $\mathrm{GH}$ and/or insulin, as indicated in the Figure legends and the cell media were changed every other day.

\section{Cell number determination}

Cell number estimation is based on the measurement of lipid content of an aliquot of cell suspension (Dole \& Meinertz 1960) and on the measurement of adipocyte diameters using an image analysis system (Optimas 6.5; Media Cybernetics, Silver-Spring, MD, USA). Before culture, fat cell diameter assessed in all experimental pigs was $50 \cdot 7 \pm 0.7 \mu \mathrm{m}$ for perirenal fat and $51 \cdot 1 \pm 1 \cdot 4 \mu \mathrm{m}$ for s.c. fat. Two pigs were also used in a preliminary study to evaluate adipocyte size variation and cell lysis (determined from the number of cells remaining after the lipid layer has been removed) during the whole culture. Fat cell size did not change during the culture (data not shown). Estimation of cell number before and during culture indicates that cell breakage occurred mainly during the first 2 days of culture (e.g. cell breakage was 36 and $40 \%$ after 2 and 4 days in culture respectively in perirenalderived adipocytes; data not shown).

\section{Glucose incorporation into lipids}

The lipogenic rate of adipocytes was estimated by quantifying the conversion of $\left[{ }^{14} \mathrm{C}\right]$ glucose into lipids as described previously (Foster et al. 1988). In brief, cells were incubated with $0 \cdot 4 \mu \mathrm{Ci} \mathrm{D-}\left[\mathrm{U}_{-}{ }^{14} \mathrm{C}\right]$ glucose at $37^{\circ} \mathrm{C}$ for $2 \mathrm{~h}$ in the absence or presence of hormones. Incubations were terminated by removing the medium, followed by immediately adding Dole's reagent. Fatty acids were then extracted according to Dole \& Meinertz (1960) and 
incorporated radioactivity was measured by liquid scintillation counting. Our preliminary experiments indicated that glucose conversion to lipids increased in a linear fashion during a $2 \mathrm{~h}$ incubation. Glucose incorporation into lipids was expressed as nanomoles glucose incorporated per $2 \mathrm{~h}$.

\section{FAS activity assay}

Adipocytes were homogenized by hand in ice-cold buffer (0.25 $\mathrm{M}$ sucrose, $1 \mathrm{mM}$ dithiothreitol, $1 \mathrm{mM}$ EDTA and protease inhibitors) using a glass-glass homogenizer. The homogenate was centrifuged at $100000 \mathrm{~g}$ for $60 \mathrm{~min}$. The supernatant was collected and the FAS (EC 2.3.1.85) assay was performed immediately or after storage at $-70^{\circ} \mathrm{C}$, as previously described (Guichard et al. 1992). The protein concentration of the cytosolic fraction was determined by using the bicinchoninic acid assay with BSA as a standard. FAS activities were expressed as nanomoles of NADPH oxidized/minute and per milligram of protein. Measurements were done in triplicate.

\section{Western blotting}

Preparation of nuclear extracts from isolated adipocytes was performed as described by Dugail (2001) and protein content was determined using BSA as standard (Bradford 1976). Adipocyte cytosolic proteins $(40 \mu \mathrm{g})$ or nuclear extract proteins $(20 \mu \mathrm{g})$ were electrophoresed under reducing conditions on 8 or 12\% SDS-polyacrylamide gels respectively, and were then electro-transferred onto Hybond $\mathrm{C}$ nitrocellulose membranes. The blots were blocked for $1 \mathrm{~h}$ in PBS-Tween $20(0 \cdot 1 \% \mathrm{w} / \mathrm{v})$ containing $5 \%$ non-fat dry milk and were then incubated overnight with a primary antibody. The FAS protein was probed with a rabbit polyclonal antibody against FAS (1:1000) (Abcam Ltd, Cambridge, UK) and membranes were rinsed three times with PBS-Tween $20(0 \cdot 1 \mathrm{v} / \mathrm{v})$. The SREBP-1 protein was detected with a mouse monoclonal antibody against amino acids 301-407 of human SREBP-1 (1:200) (NeoMarkers, Fremont, CA, USA). Membranes were rinsed three times with PBS buffer containing $0 \cdot 1 \%$ SDS, $1 \%$ Nonidet-P40 and $0.5 \%$ deoxycholic acid. Detection of the signals was performed with the ECL Western blot detection kit, with an anti-rabbit for FAS $(1: 10000)$ or an anti-mouse $(1: 2500)$ for SREBP-1 horseradish peroxidase-conjugated IgG as second antibodies. Autoradiograms were scanned and quantified with an image processor (Quantity One, V4; Bio-Rad, Hercules, CA, USA).

\section{Total RNA isolation and Northern blot hybridization}

Total cellular RNA was extracted from cultured adipocytes by the guanidinium thiocyanate method (Chomczynski \& Sacchi 1987) with modification
(Louveau et al. 1991). Twenty micrograms of total RNA were denatured in formamide and formaldehyde and subsequently separated in 1\% formaldehyde-agarose gel. RNA was then transferred overnight into a Hybond $\mathrm{N}^{+}$ membrane. Membranes were hybridized with labeled probes obtained by RTS labeling. A partial cDNA fragment encoding porcine SREBP-1 was used for probe generation, as detailed in Gondret et al. (2001). This probe, corresponding to amino acids 241-367 in human SREBP-1a, recognized both $1 \mathrm{a}$ and $1 \mathrm{c}$ isoforms. Autoradiograms for SREBP-1 were developed after 4 days. Membranes were then re-probed with a cDNA for porcine $18 \mathrm{~S}$ to assess variation in loading or transfer of RNA samples. Signals were scanned and quantified with an image processor program (Quantity One, V4; BioRad). Results are expressed as relative expression of SREBP-1 to $18 \mathrm{~S}$.

\section{Real-time RT-PCR}

After DNAse treatment, total RNA $(1.5 \mu \mathrm{g})$ was reverse transcribed using random hexamers and murine Moloney leukemia virus reverse transcriptase, according to the manufacturer's instructions (Amersham Biosciences). The design of the primers for the selected genes (FAS: forward primer, 5'-AGCCTAACTCCTCGCTGCAAT-3'; re-

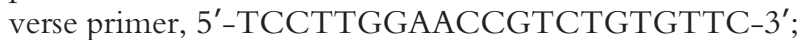
SREBP-1, forward primer: 5'-CGGACGGCTCACAA TGC-3; reverse primer, 5'-GCAAGACGGCGGATT TATTC- $3^{\prime}$ ) was done using Primer Express software (Applied Biosystems, Warrington, Cheshire, UK), based on porcine sequences (FAS: Genbank AY183428; SREBP-1: Genbank AF102873). Real-time RT-PCR analyses were performed starting with $100 \mathrm{ng}$ of reversetranscribed total RNA, and both sense and antisense primers (FAS: $500 \mathrm{nM}$, SREBP-1: $200 \mathrm{nM}$ ), in a final volume of $25 \mu$ l, using SYBR Green I PCR core reagents in an ABI PRISM 7700 Sequence Detection System instrument (Applied Biosystem). Forty cycles of amplification were performed. Absence of contamination from either genomic DNA amplification or primer dimer formation was ensured using controls without reverse transcriptase or with no DNA template. An annealing temperature of $59^{\circ} \mathrm{C}$ was used for each gene. Specificity of RT-PCR products was documented on ethidium bromide-stained agarose gel electrophoresis and resulted in a single product of the expected size (FAS: $196 \mathrm{bp}$, SREBP-1: $118 \mathrm{bp}$ ). A melting curve analysis was also performed, which resulted in single-product specific melting temperatures as follows: FAS: $87^{\circ} \mathrm{C}$; SREBP-1: $82^{\circ} \mathrm{C}$. Endogenous $18 \mathrm{~S}$ ribosomal RNA amplifications (Human 18S rRNA pre-developed TaqMan kit; Applied Biosystem) were used to normalize the expression of the selected genes. A cDNA sample of freshly isolated perirenal adipocytes was used as an inter-plate calibrator for each gene. To measure real-time PCR efficiencies, serial 


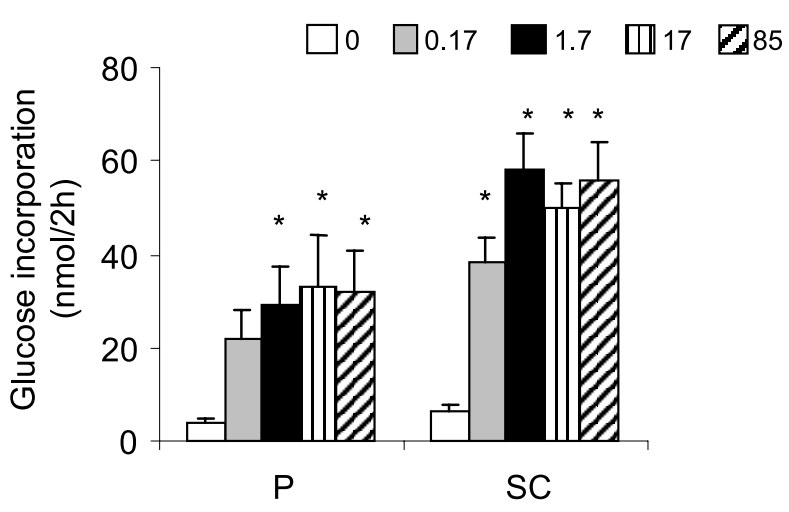

Figure 1 Dose-response of insulin-stimulated glucose incorporation in cultured adipocytes isolated from perirenal $(\mathrm{P})$ or s.c. (SC) adipose tissue. Cells were incubated in a defined medium without or with increasing concentrations of insulin $(n M)$ for 2 days. Data represent means \pm S.E.M. of experiments performed in triplicate $\left(n=4\right.$ for P; $n=5$ for SC). The asterisk $\left({ }^{*}\right)$ indicates a statistically significant difference compared with control cultures without insulin $(P<0 \cdot 05)$.

dilutions of reverse transcribed RNA (0.03-200 ng) were amplified. A line was obtained by plotting cycle threshold $\left(\mathrm{C}_{\mathrm{T}}\right)$ values as a function of starting cDNA, the slope of which was used in the equation $\mathrm{E}=10^{(1 / \mathrm{slope})}-1$ to calculate PCR efficiencies (FAS: 0.92; SREBP-1: 0.92; 18S: 1.08). Assuming that efficiencies for target genes and $18 \mathrm{~S}$ were close to 1 , the relative quantification for a target gene in comparison with a reference gene in a given sample was calculated according to the formula presented in Pfaffl (2001):

$$
\text { ratio }=2^{-\Delta \mathrm{C}_{\mathrm{T}} \text { target(sample }- \text { calibrator) } / 2-\Delta \mathrm{C}_{\mathrm{T}} 18 \mathrm{~S}(\text { sample }- \text { calibrator })}
$$

$\mathrm{C}_{\mathrm{T}}$ values are means of triplicate measurements. Experiments were repeated twice. Values obtained in hormonefree medium were arbitrarily set to 100 , and percent relative expressions of SREBP-1 and FAS genes in hormone-supplemented media were calculated.

\section{Statistical analysis}

Results were analyzed using the General Linear Model procedures of SAS (1990). The mean separation procedure used was a multiple $t$-test comparison. All data are presented as means \pm S.E.M.

\section{Results}

Initial experiments were conducted to verify that the culture system was suitable to examine hormonal regulation of lipogenesis in pig adipocytes isolated from s.c. and perirenal adipose tissue. In both sites, glucose incorporation into lipids and FAS activity were assessed in response to increasing concentrations of insulin. At the start of

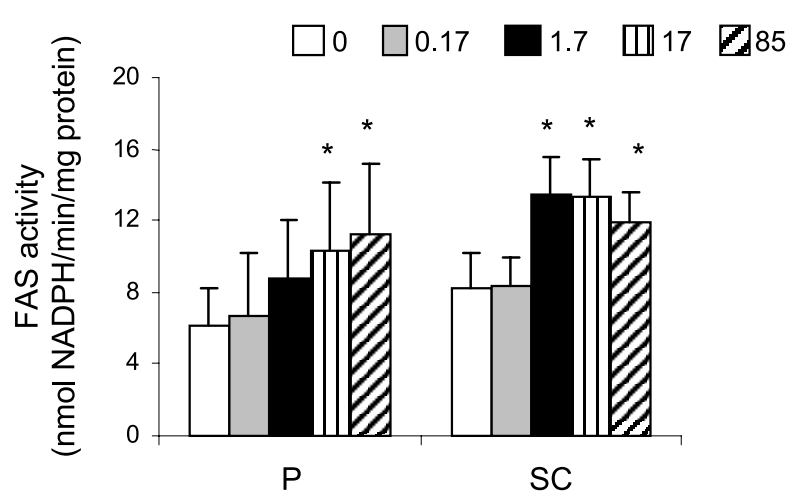

Figure 2 Dose-response of insulin-stimulated FAS activity in cultured adipocytes isolated from perirenal (P) or s.c. (SC) adipose tissue. Cells were incubated in a defined medium without or with increasing concentrations of insulin (nM) for 2 days. Data represent means \pm S.E.M. of experiments performed in triplicate $\left(n=4\right.$ for P; $n=6$ for SC). The asterisk $\left(^{*}\right)$ indicates a statistically significant difference compared with control cultures without insulin $(P<0 \cdot 05)$.

culture, basal FAS activity levels were similar in s.c. and perirenal adipocytes $(20.2 \pm 3.5$ vs $17 \cdot 4 \pm 3.8 \mathrm{nmol} / \mathrm{mg}$ protein, $P>0 \cdot 1)$, whereas basal glucose incorporation tended to be higher in s.c. than in perirenal adipocytes $(48 \cdot 4 \pm 13.6$ vs $16 \cdot 1 \pm 4 \cdot 8 \mathrm{nmol} / 2 \mathrm{~h}, P=0 \cdot 08)$. Timecourse monitoring for changes in glucose incorporation and FAS activity revealed that lipogenesis decreased throughout the culture time in basal conditions for both sites (data not shown). The incubation of s.c. or perirenal adipocytes for 2 days with insulin resulted in a dosedependent increase in glucose incorporation (Fig. 1) and FAS activity (Fig. 2), compared with cells cultured in the absence of the hormone. The stimulatory effect of insulin on glucose incorporation was significant at concentrations of 0.17 and $1.7 \mathrm{nM}$ for s.c. and perirenal adipocytes respectively. The insulin-dependent increase in FAS activity was significant at concentrations of 1.7 and $17 \mathrm{nM}$ for s.c. and perirenal adipocytes, respectively. Treatment of adipocytes from both sites with higher concentrations of insulin than those cited above led to a similar increment in lipogenesis. After 4 days of culture, a similar insulinresponsiveness profile was observed in s.c. and perirenal adipocytes (data not shown). For further analysis, s.c. and perirenal adipocytes were exposed to an insulin concentration of 1.7 and $17 \mathrm{nM}$ respectively. Freshly isolated adipocytes exposed for $2 \mathrm{~h}$ in the presence of insulin displayed higher glucose incorporation levels than cells maintained in the absence of the hormone (Fig. 3). The addition of insulin to cells that had been cultured for 2 days in the absence of the hormone provoked at least a 4 -fold increase in glucose incorporation in s.c. and perirenal adipocytes at day 3 (Fig. 3), compared with cells cultured in the absence of insulin over time. Thereafter, in both s.c. and perirenal adipocytes, there was no significant difference in glucose incorporation between cells which had 


\section{SC}

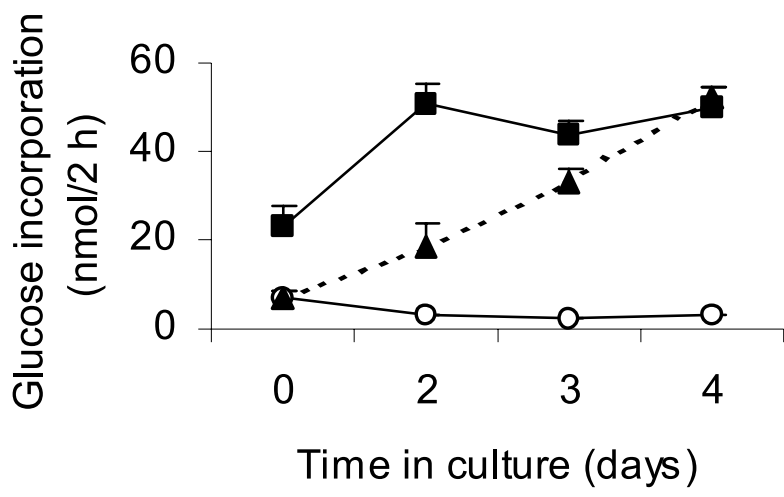

$P$

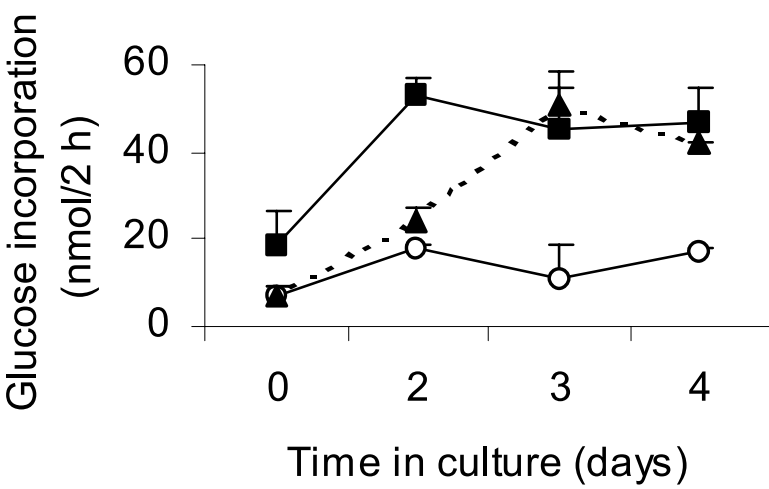

Figure 3 Effect of insulin addition on time-course incorporation of glucose into lipids in cultured adipocytes isolated from s.c. (SC) or perirenal $(\mathrm{P})$ adipose tissue. Cells were incubated in a defined medium for 2, 3 or 4 days. Insulin (1.7 and $17 \mathrm{nM}$ for adipocytes isolated from SC and $\mathrm{P}$ adipose tissue respectively) was added at the start of culture ( $\boldsymbol{\square})$ or after 2 days of culture $(\boldsymbol{\Delta})$ before glucose incorporation measurement or was not added to the culture medium $(\bigcirc)$. Data represent means \pm S.E.M. of one experiment performed in triplicate.

been insulin-treated throughout culture and those that had been insulin-treated only for 2 days. Similar profiles were elicited for FAS activity in both sites (data not shown).

Addition of $\mathrm{GH}$ for 2 or 4 days to the medium induced a decrease in insulin-stimulated glucose incorporation in s.c. and perirenal adipocytes (Fig. 4). The decline was significant $(P<0 \cdot 05)$ in s.c. adipocytes after 2 days in culture. Insulin-stimulated FAS activity was also inhibited by $\mathrm{GH}$ in both s.c. and perirenal adipocytes (Fig. 4). Nevertheless, whereas the inhibitory effect was seen on both days 2 and 4 for s.c. adipocytes, this effect was seen only on day 2 for perirenal adipocytes. On day 2, modifications observed for catalytic FAS activity were strongly paralleled by variations in FAS protein and FAS gene expression (Fig. 5). To examine the molecular signal involved in the effects of $\mathrm{GH}$ on the insulin-stimulated lipogenesis, we investigated the expression level of the SREBP-1 transcription factor in untreated cells, cells treated with optimal concentration of insulin, or cells exposed to $\mathrm{GH}(1 \mathrm{nM})$ and insulin during 2 days of culture. Whatever the donor site, cells which were cultured in the presence or the absence of $\mathrm{GH}$ and insulin displayed similar SREBP-1 mRNA levels, when evaluated by Northern blot analysis and by the highly sensitive real-time RT-PCR analysis (Fig. 5). In an additional experiment, we examined SREBP-1 protein expression in cells cultured for 2 days in the presence or absence of the hormones. Nuclear content of the cleaved form of SREBP-1 protein (showing a size closely similar to that of rat SREBP-1c (Azzout-Marniche et al. 2000)) was not different between untreated cells, cells treated with insulin alone and cells treated with both insulin and GH (Fig. 6).

\section{Discussion}

Although several studies indicate that the $\mathrm{GH}$ effects on porcine adipose tissue involve a marked decrease in the activity of several insulin-stimulated lipogenic enzymes including FAS, few studies have examined the mechanism by which GH affects insulin action on lipogenesis in adipocytes. For the first time in meat-producing animals, the present study aimed to determine whether the effects of $\mathrm{GH}$ and/or insulin on FAS activity could be mediated by SREBP-1 in isolated adipocytes. Investigating these effects requires a system in which adipocytes can be maintained metabolically active for several days. Indeed, $\mathrm{GH}$ exerts a chronic control of adipocyte function. Moreover, one can assume that the half-life of FAS is about 40-50 $\mathrm{h}$ in porcine adipocytes as in rodents (Weiss et al. 1980). In pigs, in vitro studies have concerned only short-term incubation of adipocytes $(<24 \mathrm{~h})$ (Etherton \& Chung 1981, Smith et al. 1996, Wang et al. 1999) or of adipose tissue fragments $(<48 \mathrm{~h}$ ) (Walton \& Etherton 1986). In the current study, we have provided evidence that cultured adipocytes can be used as a model for studying hormonal control of lipogenesis in pigs.

\section{Insulin responsiveness of isolated porcine adipocytes}

The present experiments indicate that after at least 2 days in culture, isolated adipocytes maintained the capacity to incorporate glucose into total lipids and displayed FAS activity at rates increasing with insulin concentrations in the medium. Interestingly, mature cells cultured in the absence of insulin, when challenged with the hormone after 2 days, displayed a marked increase in lipogenesis, thus demonstrating the ability to reinitiate insulin stimulation from a basal state. The response to insulin was also 
SC

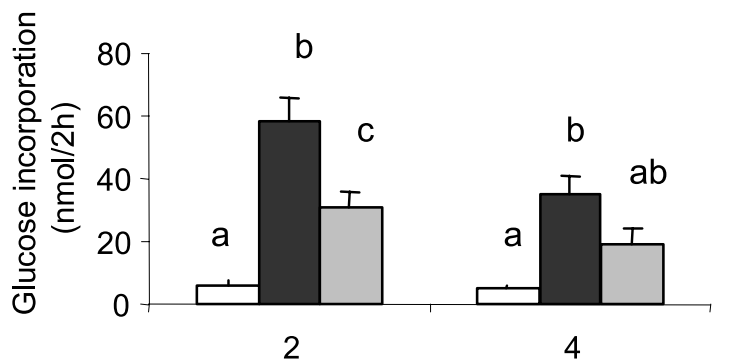

Time in culture (days)

$\mathrm{P}$

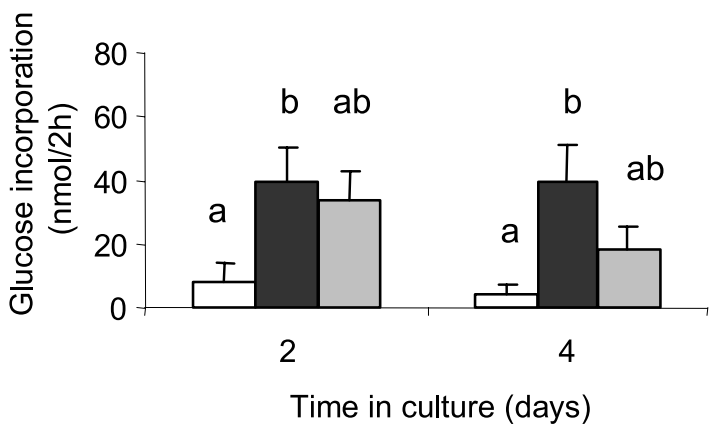

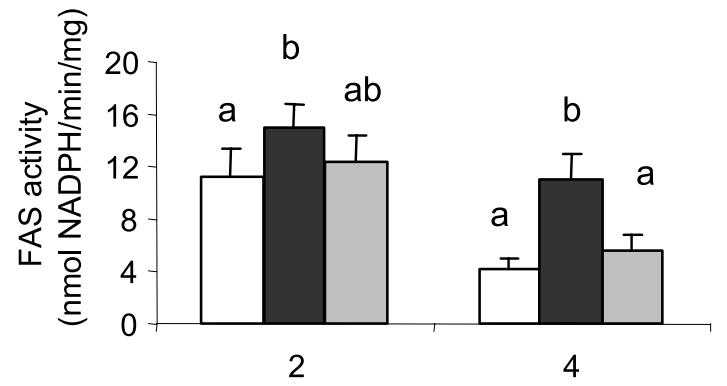

Time in culture (days)

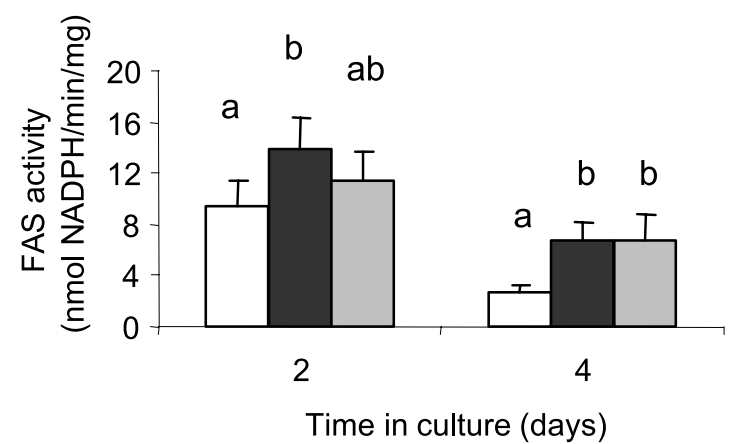

Figure 4 Effect of $\mathrm{GH}$ on insulin-stimulated glucose incorporation and FAS activity in cultured adipocytes isolated from s.c. (SC) or perirenal $(\mathrm{P})$ adipose tissue. At the start of culture, cells were incubated in a defined-medium without or with insulin ( $1.7 \mathrm{and} 17 \mathrm{nM}$ for adipocytes isolated from SC and P adipose tissue respectively) in the absence or presence of GH (1 nM). Data represent means \pm S.E.M. of experiments performed in triplicate (glucose incorporation: $n=4$ for P; $n=5$ for SC; FAS activity: $n=8$ for P and SC). Within any one day of culture, means with different letters are significantly different $(P<0 \cdot 05)$. Open bars: defined medium; black bars: defined medium supplemented with insulin alone; gray bars: defined medium supplemented with insulin and $\mathrm{GH}$.

observed with freshly isolated adipocytes after short-term acute incubation. Altogether, these observations indicate that the adipocytes were still metabolically active. The magnitude of glucose incorporation found in this study is in the range of levels that have been reported previously in primary cultures of rat (Briquet-Laugier et al. 1994) or human adipocytes (Moustaid et al. 1996). In the present study, glucose incorporation and FAS activity were regulated by insulin in a dose-dependent manner. An optimum response for FAS activity was reached for a concentration as low as $1.7 \mathrm{nM}$ in s.c. adipocytes, whereas higher concentrations of insulin are often used in isolated adipocytes from other species, such as rat (Briquet-Laugier et al. 1994) or human (Moustaïd et al. 1996). In pigs, adipose tissue and/or adipocyte response to insulin has been often reported to be inconsistent (Mills 1999), with reports of absence of any responsiveness (Rule et al. 1987, Benmansour et al. 1991), little response (Liu et al. 1989, Harris et al. 1993) but not related to insulin concentrations
(Mersmann \& $\mathrm{Hu}$ 1987), or clear stimulation of glucose incorporation into fatty acids and lipogenesis in vitro (Walton \& Etherton 1986, Smith et al. 1996, Mills 1999). One possible explanation for these discrepancies is that an exaggerated basal rate of fatty acid synthesis could mask insulin responses in porcine adipocytes (Mills 1999). The more likely explanation is that the culture medium may interfere with the insulin response. In previous experiments, BSA has been shown to interfere with insulin response in pig adipose tissue slices (Walton \& Etherton 1986, Mersmann \& Hu 1987). For this reason, a BSA-free cell medium was used (Walton et al. 1986).

\section{Donor site effects on insulin sensitivity}

We have currently demonstrated that perirenal-derived adipocytes were less sensitive to insulin than s.c.-derived cells, in that the dose response to acute insulin challenge was shifted to the right by an order of magnitude for both 
A

FAS

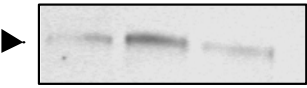

Insulin - $\quad+\quad+$

$\mathrm{GH}$

P

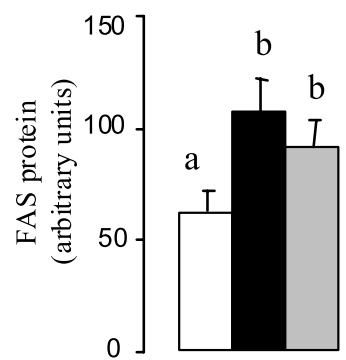

C

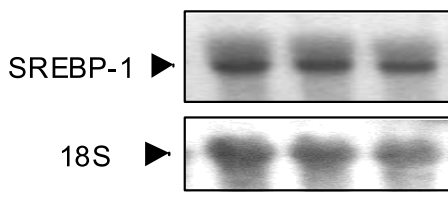

$\begin{array}{llll}\text { Insulin } & - & + & + \\ \mathrm{GH} & - & - & +\end{array}$

P

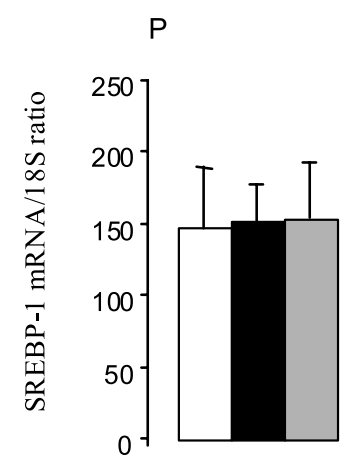

$$
\text { , }
$$

B
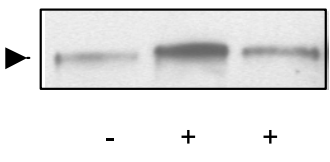

$-\quad+\quad+$

SC

b

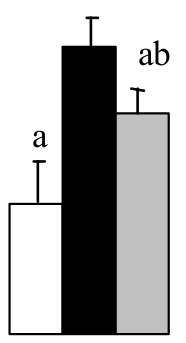

$\mathrm{GH}$

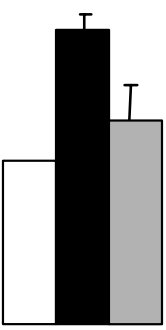

D

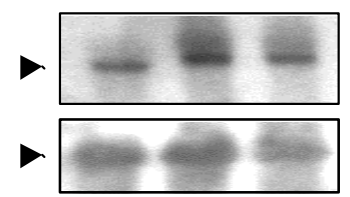

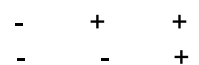

SC

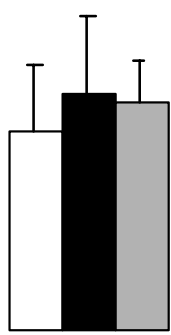

Insulin

$P$

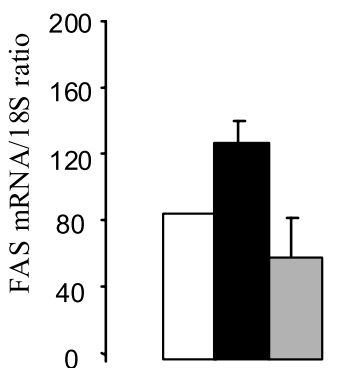

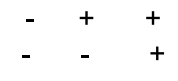

S

Figure 5 Effect of $\mathrm{GH}$ and insulin on FAS expression and SREBP-1 mRNA levels in adipocytes isolated from s.c. (SC) or perirenal $(\mathrm{P})$ adipose tissue. At the start of culture, cells were incubated in a defined-medium without or with insulin (1.7 and $17 \mathrm{nM}$ for adipocytes isolated from SC and P adipose tissue respectively) in the absence or presence of $\mathrm{GH}$ ( $1 \mathrm{nM}$ ). Measurements were performed after 2 days of culture. (A) Western blot of FAS protein ( $n=4$ in P or SC adipose tissue). (B) FAS mRNA level was determined by real-time RT-PCR and quantified as described in Materials and Methods ( $n=2$ in P or SC adipose tissue). (C) SREBP-1 mRNA level was determined by Northern blot analysis and densitometric values on the autoradiogram were quantified by image analysis ( $n=5$ in P or SC adipose tissue). (D) SREBP-1 mRNA level was determined by real-time RT-PCR and quantified as described in Materials and Methods ( $n=2$ in P or SC adipose tissue). Representative blots are shown, together with the mean quantification of the signals (associated with S.E.M.). Open bars: defined medium; black bars: defined medium supplemented with insulin alone; gray bars: defined medium supplemented with insulin and $\mathrm{GH}$. 


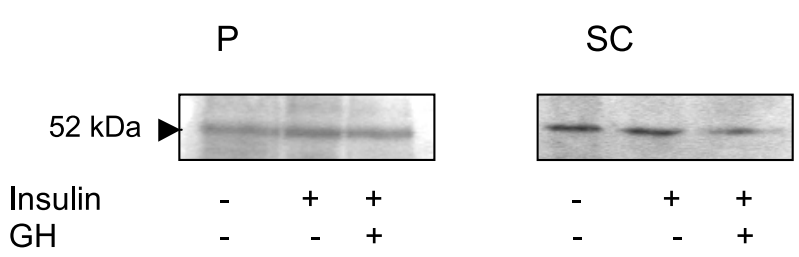

Figure 6 An additional experiment on the effect of $\mathrm{GH}$ and insulin on SREBP-1 protein. At the start of culture, adipocytes isolated from s.c. (SC) or perirenal $(\mathrm{P})$ adipose tissue were incubated in a defined medium without or with insulin (1.7 and $17 \mathrm{nM}$ for adipocytes isolated from SC and $\mathrm{P}$ adipose tissue respectively) in the absence or presence of $\mathrm{GH}(1 \mathrm{nM})$. Measurements were performed after 2 days of culture. SREBP-1 protein was detected by Western blot as described in Materials and Methods. Measurements were performed in duplicate.

glucose incorporation and FAS activity. Because cells were cultured under identical environmental conditions, it is likely that the observed difference between the two depots reflects a difference in intrinsic features of cells. These observations support regional differences in metabolic function of adipose tissue that have been reported by several investigators (Arner 1997). There are, for example, known differences in the lipolytic response to adrenergic stimulation between visceral and s.c. adipose tissue in human. The mechanisms underlying difference in lipogenic response in our study remain to be clarified. Differences in insulin sensitivity between donor sites could not be attributed to variation in s.c. and perirenal adipocyte sizes but could involve differences in cell surface insulin receptor number or affinity, as insulin itself regulates adipocyte sensitivity to the biological action of insulin by negative modulation of the number of cell surface insulin receptors (Marshall et al. 1984). Difference in the level of expression of insulin signaling molecules could also contribute to the reduced insulin sensitivity of perirenal adipocytes compared with other cells (Lefebvre et al. 1998).

\section{Mechanism involved in GH and insulin actions on lipogenesis in isolated porcine adipocytes}

In agreement with previous observations in pig adipose tissue (Walton et al. 1986) and 3T3-F442A murine adipocytes (Yin et al. 2001), we have found that GH antagonized the stimulatory effect of insulin on glucose incorporation into lipids and FAS activity in primary cultures of pig adipocytes isolated from both perirenal and s.c. adipose tissue. Changes in FAS mRNA and protein levels in the presence or absence of these hormones are observed in parallel. Studies performed in various mammalian species have led to the conclusion that FAS is controlled primarily at the level of gene transcription (Semenkovich 1997); however, the mechanism by which GH interacts with insulin action on FAS gene transcription has not been elucidated yet. We speculated that
SREBP-1c was a possible mediator of the action of insulin and $\mathrm{GH}$ on lipogenesis in porcine adipocytes. The SREBP-1 gene gives rise to two separate protein isoforms (SREBP-1a and SREBP-1c) through alternative splicing of the first exon (Brown \& Goldstein 1997). The cDNA probe we used recognized both $1 \mathrm{a}$ and $1 \mathrm{c}$ isoforms; however, based on the relative levels of each isoform expression in mammalian tissues (Brown \& Goldstein 1997), the observed signal corresponded very probably to SREBP-1c mRNA. The pattern of expression of SREBP-1 we observed in adipocytes, i.e. two bands of approximately $5 \mathrm{~kb}$ in length, is similar to that reported for pig adipose tissue (Ding et al. 2000, Gondret et al. 2001) and for freshly isolated rat adipocytes (Palmer et al. 2002).

In a situation of clear insulin stimulation or GH inhibition of FAS gene expression, protein content and catalytic activity, we failed to evidence any significant variation in SREBP-1 mRNA level in perirenal or s.c. isolated mature adipocytes. In line with our results, $\mathrm{GH}$ inhibits FAS gene expression at a step distal to the expression of SREBP-1 in differentiating primary rat adipocytes (Hansen et al. 1998). The absence of any apparent effect of insulin on SREBP-1 transcription contrasts with the general dogma that SREBP-1 is an important mediator of insulin action. It agrees, however, with recent findings reported in freshly isolated rat adipocytes under conditions where FAS expression is stimulated by insulin (Palmer et al. 2002). The basis of these discrepancies is not clear. A possible explanation is that the principal mechanism by which insulin stimulates lipogenesis differs between isolated mature adipocytes and adipocyte cell lines and(or) between cell types. Indeed, the regulation of SREBP-1 has been studied mostly in 3T3-L1 adipocytes (Kim et al. 1998, Le Lay et al. 2002) and in rat isolated hepatocytes (Foretz et al. 1999a,b, Azzout-Marniche et al. 2000). One can also argue that the time selected for mRNA analysis in the current study (2 or 4 days after insulin addition) was not appropriate to show any effects of insulin on SREBP-1 mRNA, since many transcripts exhibit transient changes in response to a stimulus. However, this hypothesis is unlikely. First, even though a $2 \mathrm{~h}$ exposure to insulin is sufficient to induce a significant increase in SREBP-1 mRNA levels (Kim et al. 1998) in fully differentiated 3T3-L1 adipocytes, an increase in SREBP-1 expression is still observed after a $48 \mathrm{~h}$ exposure to insulin (Le Lay et al. 2002). Secondly, Palmer et al. (2002) failed to detect any change in SREBP-1 mRNA expression in isolated rat adipocytes despite the use of a shorter incubation time (4-6 h) with insulin. It is important to note that the time in our study was selected because our aim was to study GH effects on lipogenic genes. Interestingly, at least in hepatocytes, detectable amounts of nuclear SREBP-1c are still present after a period of $14 \mathrm{~h}$ without insulin (Azzout-Marniche et al. 2000). However, we did not detect any change in the level of the cleaved form of SREBP-1 protein in 
response to insulin treatment, which confirmed, at least, the absence of variation observed in mRNA levels. However, we cannot exclude that insulin could act on SREBP-1 via post-translational mechanisms. A possible effect of insulin to induce phosphorylation of SREBP-1 protein on serine residues by mitogen-activated protein kinase was mentioned in vitro using transfection in a cell line (Kim et al. 1998, Kotzka et al. 1998, 2000). In cultured hepatocytes, SREBP-1c could rather be phosphorylated by downstream kinases of phosphatidylinositol-3 kinase (Foufelle \& Ferré 2002); however, ongoing SREBP-1c synthesis is necessary to maintain a high level of SREBP-1c in both the membrane and nuclear compartment in rat hepatocytes (Azzout-Marniche et al. 2000). In conclusion, it appears unlikely that SREBP-1 transcription is involved in GH or insulin action on FAS activity in isolated porcine adipocytes. Whether both hormones could regulate SREBP-1 at a post-translational level in pig adipocytes remains to be demonstrated.

\section{Acknowledgements}

We wish to thank F Pontrucher and C Tréfeu for expert technical assistance. F Edno and D Gardan are also gratefully acknowledged for their contribution to the initial experiments. Pituitary porcine GH was generously supplied by Dr A Parlow (NHPP, NIDDK).

\section{References}

Arner P 1997 Obesity of the adipocyte. Regional adipocity in man. Journal of Endocrinology 155 191-192.

Azzout-Marniche D, Becard D, Guichard C, Foretz M, Ferré P \& Foufelle F 2000 Insulin effects on sterol regulatory-element-binding protein-1c (SREBP-1c) transcriptional activity in rat hepatocytes. Biochemical Journal 350 389-393.

Benmansour NM, Demarne Y, Lecourtier MJ \& Lhuillery C 1991 Effects of dietary fat and adipose tissue location on insulin action in young boar adipocytes. International Journal of Biochemistry 23 499-506.

Bradford MM 1976 A rapid and sensitive method for the quantitation of microgram quantities of protein utilizing the principle of protein-dye binding. Analytical Biochemistry 72 248-254.

Briquet-Laugier V, Dugail I, Ardouin B, Le Lièpvre X, Lavau M \& Quignard-Boulangé A 1994 Evidence for a sustained genetic effect on fat storage capacity in cultured adipose cells from Zucker rats. American Journal of Physiology 267 E439-E446.

Brown MS \& Goldstein JL 1997 The SREBP pathway: regulation of cholesterol metabolism by proteolysis of a membrane-bound transcription factor. Cell 89 331-340.

Chomczynski P \& Sacchi N 1987 Single-step method of RNA isolation by acid guanidinium thiocyanate-phenol-chloroform extraction. Analytical Biochemistry 162 156-159.

Ding ST, Schinckel AP, Weber TE \& Mersmann HJ 2000 Expression of porcine transcription factors and genes related to fatty acid metabolism in different tissues and genetic populations. Journal of Animal Science 78 2127-2134.

Dole VP \& Meinertz H 1960 Microdetermination of long-chain fatty-acids in plasma and tissues. Journal of Biological Chemistry 235 2595-2599.
Donkin SS, Chiu PY, Yin D, Louveau I, Swencki B, Vockroth J, Evock-Clover CM, Peters JL \& Etherton TD 1996 Porcine somatotropin differentially down-regulates expression of the GLUT4 and fatty acid synthase genes in pig adipose tissue. Journal of Nutrition 126 2568-2577.

Dugail I 2001 Transfection of adipocytes and preparation of nuclear extracts. Methods in Molecular Biology 155 141-146.

Dunshea FR, Harris DM, Bauman DE, Boyd RD \& Bell AW 1992 Effect of porcine somatotropin on in vivo glucose kinetics and lipogenesis in growing pigs. Journal of Animal Science 70 141-151.

Etherton TD 2000 The biology of somatotropin in adipose tissue growth and nutrient partitioning. Journal of Nutrition 130 2623-2625.

Etherton TD \& Chung CS 1981 Preparation, characterization, and insulin sensitivity of isolated swine adipocytes: comparison with adipose tissue slices. Journal of Lipid Research 22 1053-1059.

Etherton TD \& Bauman DE 1998 Biology of somatotropin in growth and lactation of domestic animals. Physiological Reviews 78 745-761.

Foretz M, Guichard C, Ferré P \& Foufelle F 1999a Sterol regulatory element binding protein-1c is a major mediator of insulin action on the hepatic expression of glucokinase and lipogenesis-related genes. PNAS 96 12737-12742.

Foretz M, Pacot C, Dugail I, Lemarchand P, Guichard C, Le Lièpvre X, Berthelier-Lubrano C, Spiegelman B, Kim JB, Ferré P et al. $1999 b$ ADD1/SREBP-1c is required in the activation of hepatic lipogenic gene expression by glucose. Molecular and Cellular Biology 19 3760-3768.

Foster CM, Hale PM, Jing HW \& Schwartz J 1988 Effects of human growth hormone on insulin-stimulated glucose metabolism in 3T3-F442A adipocytes. Endocrinology 123 1082-1088.

Foufelle F \& Ferré P 2002 New perspectives in the regulation of hepatic glycolytic and lipogenic genes by insulin and glucose: a role for the transcription factor SREBP-1c. Biochemical Journal 366 377-391.

Gondret F, Ferré P \& Dugail I 2001 ADD-1/SREBP-1 is a major determinant of tissue differential lipogenic capacity in mammalian and avian species. Journal of Lipid Research 42 106-113.

Guichard C, Dugail I, Le Lièpvre X \& Lavau M 1992 Genetic regulation of fatty acid synthetase expression in adipose tissue: over-transcription of the gene in genetically obese rats. Journal of Lipid Research 33 679-687.

Hansen LH, Madsen B, Teisner B, Nielsen JH \& Billestrup N 1998 Characterization of the inhibitory effect of growth hormone on primary preadipocyte differentiation. Molecular Endocrinology 12 1140-1149.

Harris DM, Dunshea FR, Bauman DE, Boyd RD, Wang SY, Johnson PA \& Clarke SD 1993 Effect of in vivo somatotropin treatment of growing pigs on adipose tissue lipogenesis. Journal of Animal Science 71 3293-3300.

Kim JB, Sarraf P, Wright M, Yao KM, Mueller E, Solanes G, Lowell BB \& Spiegelman BM 1998 Nutritional and insulin regulation of fatty acid synthetase and leptin gene expression through ADD1/ SREBP1. Journal of Clinical Investigation 101 1-9.

Kotzka J, Muller-Wieland D, Koponen A, Njamen D, Kremer L, Roth G, Munck M, Knebel B \& Krone W 1998 ADD1/ SREBP-1c mediates insulin-induced gene expression linked to the MAP kinase pathway. Biochemical and Biophysical Research Communications 249 375-379.

Kotzka J, Muller-Wieland D, Roth G, Kremer L, Munck M, Schurmann S, Knebel B \& Krone W 2000 Sterol regulatory element binding proteins (SREBP)-1a and SREBP-2 are linked to the MAP-kinase cascade. Journal of Lipid Research 41 99-108.

Lefebvre AM, Laville M, Vega N, Riou JP, Van Gaal L, Auwerx J \& Vidal H 1998 Depot-specific differences in adipose tissue gene expression in lean and obese subjects. Diabetes 47 98-103.

Le Lay S, Lefrère I, Trautwein C, Dugail I \& Krief S 2002 Insulin and sterol regulatory element binding protein-1c (SREBP-1c) 
regulation of gene expression in 3T3-L1 adipocytes: identification of CCAAT/enhancer-binding protein beta as an SREBP-1c target. Journal of Biological Chemistry 277 35625-35634.

Liu CY, Boyer JL \& Mills SE 1989 Acute effects of beta-adrenergic agonists on porcine adipocyte metabolism in vitro. Journal of Animal Science 67 2930-2936.

Louveau I, Chaudhuri S \& Etherton TD 1991 An improved method for isolating RNA from porcine adipose tissue. Analytical Biochemistry 196 308-310.

Magri KA, Adamo M, Leroith D \& Etherton TD 1990 The inhibition of insulin action and glucose metabolism by porcine growth hormone in porcine adipocytes is not the result of any decrease in insulin binding or insulin receptor kinase activity. Biochemical Journal 266 107-113.

Marshall S, Garvey WT \& Geller M 1984 Primary culture of isolated adipocytes: a new model to study insulin receptor regulation and insulin action. Journal of Biological Chemistry $2596376-6384$.

Mersmann HJ \& Hu CY 1987 Factors affecting measurements of glucose metabolism and lipolytic rates in porcine adipose tissue slices in vitro. Journal of Animal Science 64 148-164.

Mildner AM \& Clarke SD 1991 Porcine fatty acid synthase: cloning of a complementary DNA, tissue distribution of its mRNA and suppression of expression by somatotropin and dietary protein. Journal of Nutrition 121 900-907.

Mills SE 1999 Regulation of porcine adipocyte metabolism by insulin and adenosine. Journal of Animal Science 77 3201-3207.

Moustaïd N, Jones BH \& Taylor JW 1996 Insulin increases lipogenic enzyme activity in human adipocytes in primary culture. Journal of Nutrition 126 865-870.

Palmer DG, Rutter GA \& Tavaré JM 2002 Insulin-stimulated fatty acid synthase gene expression does not require increased sterol response element binding protein 1 transcription in primary adipocytes. Biochemical and Biophysical Research Communications 291 439-443.

Pfaffl MW 2001 A new mathematical model for relative quantification in real-time RT-PCR. Nucleic Acids Research 29 2003-2007.

Rule DC, Smith SB \& Mersmann HJ 1987 Effects of adrenergic agonists and insulin on porcine adipose tissue lipid metabolism in vitro. Journal of Animal Science 65 136-149.
SAS 1990 User's Guide. Cary, NC; Statistical Analysis System Institute.

Semenkovich CF 1997 Regulation of fatty acid synthase. Progress in Lipid Research 36 43-53.

Smith DR, Knabe DA \& Smith SB 1996 Depression of lipogenesis in swine adipose tissue by specific dietary fatty acids. Journal of Animal Science 74 975-983.

Villafuerte BC, Fine JB, Bai Y, Zhao W, Fleming S \& DiGirolomo M 2000 Expressions of leptin and insulin-like growth factor-I are highly correlated and region-specific in adipose tissue of growing rats. Obesity Research 8 646-655.

Walton PE \& Etherton TD 1986 Stimulation of lipogenesis by insulin in swine adipose tissue: antagonism by porcine growth hormone. Journal of Animal Science 62 1584-1595.

Walton PE, Etherton TD \& Evock CM 1986 Antagonism of insulin action in cultured pig adipose tissue by pituitary and recombinant porcine growth hormone: potentiation by hydrocortisone. Endocrinology 118 2577-2581.

Wang Y, Fried SK, Petersen RN \& Schoknecht PA 1999 Somatotropin regulates adipose tissue metabolism in neonatal swine. Journal of Nutrition 129 139-145.

Weiss GH, Rosen OM \& Rubin CS 1980 Regulation of fatty acid synthetase concentration and activity during adipocyte differentiation. Studies on 3T3-L1 cells. Journal of Biological Chemistry 255 4751-4757.

Yin D, Clarke SD, Peters JL \& Etherton TD 1998 Somatotropindependent decrease in fatty acid synthase mRNA abundance in 3T3-F442A adipocytes is the result of a decrease in both gene transcription and mRNA stability. Biochemical Journal 331 815-820.

Yin D, Griffin MJ \& Etherton TD 2001 Analysis of the signal pathways involved in the regulation of fatty acid synthase gene expression by insulin and somatotropin. Journal of Animal Science 79 1194-1200.

Received in final form 8 February 2004

Accepted 10 February 2004

Made available online as an

Accepted Preprint 16 February 2004 